\title{
Why do Mothers Continue to Die? Passing the Buck
}

\author{
Gunawardana $@$
}

\section{INTRODUCTION}

Why is the Reduction of Maternal Deaths Important? A maternal death is not only a tragedy to the family but also impacts negatively on the society. Additionally, it is an indicator that is utilized to measure the overall health of a population and is used to compare the health status of countries globally ${ }^{1,2,3}$.

Even in resource-poor countries, avoiding maternal deaths is possible. However, this requires the correct vision, the right effort, and availability of relevant evidence on which the preventive strategies could be based. $A d h o c$ and superficial information on maternal deaths is not enough; factors contributing or leading to the deaths need to be understood. Lessons learnt from scientific inquiries into maternal deaths lead to practical ways of addressing and preventing similar events.

Global Scenario: Of the 200 million women who conceive annually 300,000 die as a result of the complications of pregnancy and childbirth, accounting for about 830 maternal deaths a day, globally. Maternal mortality is higher in developing countries and poorer communities, accounting up to $99 \%$ of the total maternal deaths ${ }^{4}$.

The lifetime risk of maternal death in high-income countries is 1 in 6000 , compared to 1 in 40 in low-income countries. Sub-Saharan countries suffer from the highest maternal mortality ratio, which is 547 maternal deaths per
100,000 live births, or 201,000 maternal deaths a year. This is two thirds $(66 \%)$ of all maternal deaths. South Asia follows, with a maternal mortality ratio of $182 / 100,000$ live births, or 66,000 maternal deaths a year, accounting for $22 \%$ of the global total ${ }^{5}$.

Lowest maternal mortality ratio (MMR) in developed countries is recorded in Finland and Poland which is 3 per 100,000 live births. The USA has the highest MMR (14/100,000) amongst developed countries. Some developing countries have a much higher maternal mortality ratio; Sierra Leone 1360, South Sudan 789, Somalia 732, India 174 per 100,000 live births. Sri Lanka has a MMR of 33.8 per 100,000 live births, this is the lowest rate in South Asia $^{6}$.

Sri Lankan Situation: Maternal mortality has fallen strikingly from approximately 2000 per 100,000 live births in 1930 to 33.8 per 100,000 live births by 2016 . Even though the rate of decline was steep from 1930s to 1970 s, it has become less marked thereafter ${ }^{7,8,9}$. The annual rate of reduction of the MMR seems to have reached a plateau in Sri Lanka.

Safe motherhood: Quo Vadis - A survey done in Anuradhapura

Infrastructure and manpower play a major role in providing quality maternal care that is needed to reduce MMR ${ }^{1}$. In 1993, there were 16 maternal deaths in the district of Anuradhapura, out of which 13 deaths were due to substandard care. In 2015, MMR of the Anuradhapura district was 39 per 100,000 live births while the respective national figure was 33.7 per 100,000 live births (Figure 1).

\section{Figure 1 - Comparison of MMR of Anuradhapura district and Sri Lanka} 2001-2015

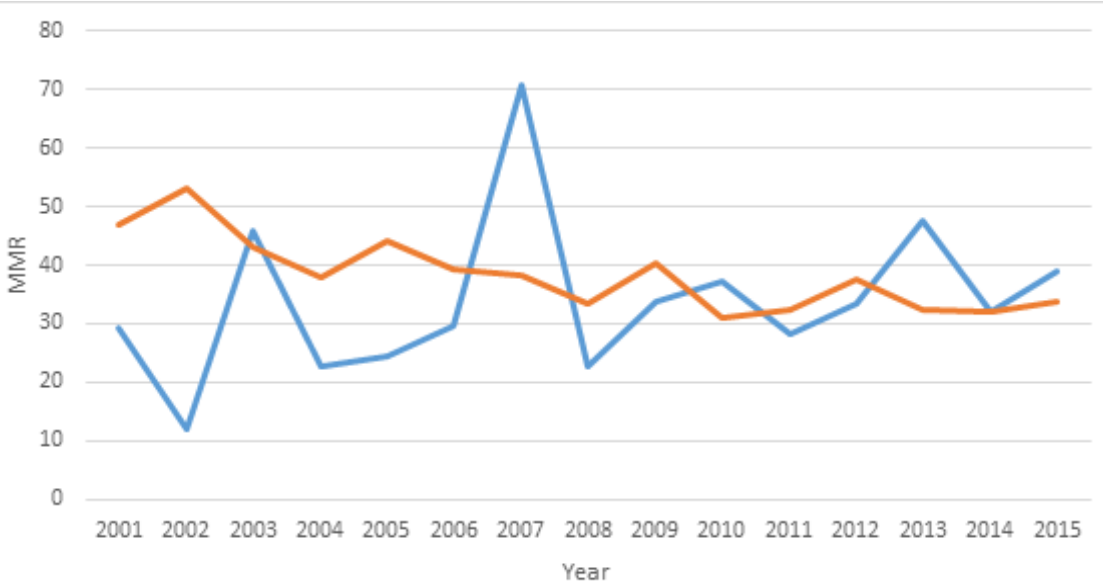

DOI: https://orcid.org/0000

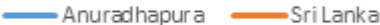

essor of Obstetrics and Gynaecology and Chair, Department of Obstetrics and

Gynaecology, Faculty of Medicine, University of Peradeniya.

E mail:

https://orcid.org/0000-0001-9306-6508

Competing interest: The author report no conflict of interest 
A survey to assess the infrastructure and manpower needs for an optimal maternal care was carried out in all hospitals under the purview of the Regional Director of Health Services (RDHS), Anuradhapura in 1994. This was conducted using an intervieweradministered questionnaire based on the WHO technical guide for essential elements of obstetric care at first referral level ${ }^{13}$. The questionnaire was administered to all health personnel at each institute.

Results revealed that only two hospitals, Padaviya and Kahatagasdegiliya fulfilled the criteria recommended by the WHO to anticipate safe deliveries. Based on the findings of this survey, a set of recommendations were developed and handed over to the local health authorities. The same survey repeated in 2017, although the number of hospitals included were 36 in 1994 there were 35 hospitals in operation in 2017.

Infrastructure Facilities: Water supply, electricity supply, availability of refrigerators, telephone and ambulance services were assessed in detail (Table 1). In assessing the availability of water, we assessed if pipe borne water was available and if stock tanks were available. In 1994 water supply was the main deficiency in 21 hospitals (58\%). The standards of power supply such as availability of back up modes like generators were not satisfactory in $6(17 \%)$ of the hospitals in 2017.

The accommodation provided to different categories of staff was not uniform. There was a lack of separate housing for nurses and midwives, both in 1994 and 2017. However, there were adequate accommodation facilities for doctors. While there was an overall improvement in the facilities between the two survey years, deficiencies existed in relation to the quality of availability. For example, despite the availability, the service readiness of the ambulances was questionable.

Human Resources: In 1994 there were 160 doctors including RMO's, 168 nurses and 93 midwives to serve the population (Table 2). In contrast, in 2017 there were 165 doctors including
12 RMO's, 392 nurses and 84 midwives. Midwifery carders were not satisfactorily filled in both years $(72 \%$ in 1994 and 51\% in 2017).

Even though the numbers of nurses were in excess of the allocated cadre, distribution was not uniform. There were no nursing officers available in divisional hospitals Ranorawa, Pairimaduwa and Kapugollewa in 2017. The poorly resourced hospitals in terms of manpower were the rural hospitals that serve as the first contact health care institutes for patients presenting with emergencies. In addition, health care providers lacked skills and knowledge to perform resuscitation procedures and instead, resorted to primitive and traditional techniques. With regard to obstetric exposure of medical officers (as an intern, $\mathrm{RHO}$ or $\mathrm{SHO}$ ), there

Table 1 - Availability of infrastructure

\begin{tabular}{|lllll|}
\hline & \multicolumn{2}{c}{1994 (36 Hospitals) } & \multicolumn{2}{c|}{2017 (35 Hospitals) } \\
& $\begin{array}{l}\text { Nominal } \\
\text { availability }\end{array}$ & $\begin{array}{l}\text { Out of order } / \\
\text { Inadequate } \\
\text { supply }\end{array}$ & $\begin{array}{l}\text { Nominal } \\
\text { availability }\end{array}$ & $\begin{array}{l}\text { Out of order } / \\
\text { Inadequate } \\
\text { supply }\end{array}$ \\
\hline Infrastructures & $\mathrm{N} \mathrm{( \% )}$ & $\mathrm{N}(\%)$ & $\mathrm{N}(\%)$ & $\mathrm{N}(\%)$ \\
\hline $\begin{array}{l}\text { Power supply } \\
\text { Water supply }\end{array}$ & $34(94 \%)$ & 00 & $35(100 \%)$ & $06(17 \%)$ \\
Ambulance & $36(100 \%)$ & $21(58 \%)$ & $35(100 \%)$ & $08(23 \%)$ \\
Refrigerator & $24(78 \%)$ & $04(11 \%)$ & $35(100 \%)$ & 00 \\
Telephone & $24(75 \%)$ & $03(8 \%)$ & $34(97 \%)$ & $03(9 \%)$ \\
& $22(67 \%)$ & $02(5 \%)$ & $32(91 \%)$ & $09(26 \%)$ \\
Accommodation & Available & Not available & Available & Not available \\
& $\mathrm{N} \mathrm{( \% )}$ & N (\%) & N (\%) & N (\%) \\
\hline $\begin{array}{l}\text { OIC (MOIC) } \\
\text { Nurses }\end{array}$ & $36(100 \%)$ & 00 & $35(100 \%)$ & 00 \\
Midwives & $10(28 \%)$ & $26(\%)$ & $20(57 \%)$ & $15(\%)$ \\
& $20(56 \%)$ & $16(\%)$ & $22(63 \%)$ & $13(\%)$ \\
\hline
\end{tabular}

Table 2 - Availability of human resources

\begin{tabular}{|lcccc|}
\hline \multicolumn{1}{|c}{ Resources } & \multicolumn{2}{c}{$1994(36$ Hospitals) } & \multicolumn{2}{c|}{2017 (35 Hospitals) } \\
\hline Human Resources & $\begin{array}{c}\text { Available } \\
\text { number }\end{array}$ & $\begin{array}{c}\text { Approved } \\
\text { Cadre }\end{array}$ & $\begin{array}{c}\text { Available } \\
\text { number }\end{array}$ & $\begin{array}{c}\text { Approved } \\
\text { Cadre }\end{array}$ \\
\hline Doctors - 1.MO & $79(65 \%)$ & 121 & $153(72 \%)$ & 212 \\
\multicolumn{1}{|c|}{ - RMO } & $81(125 \%)$ & 55 & 12 & NA \\
Nurses & $168(154 \%)$ & 109 & $392(103 \%)$ & 379 \\
Midwives & $93(72 \%)$ & 129 & $84(51 \%)$ & 164 \\
\hline
\end{tabular}

was no apparent improvement in 2017 (27 hospitals) when compared to 1994 (24 hospitals). However, there was a substantial improvement in performing manual removal of retained placenta and in-ward investigation of urine for protein and reducing substances. an improvement in terms of emergency care and availability of necessary instruments (Table 3). In comparison to 1994 , there was an improvement in the availability of emergency trays, oxygen supply, suction apparatuses, and neonatal resuscitation facilities in 2017. However, in 2017, resuscitation and assisted deliveries could not be performed in one hospital (Divisional hospital, Ranorawa) due to the lack of oxygen masks and suction apparatuses.
Instruments and Drugs: There was 
In relation to sterilization facilities, only 7 out of 36 hospitals $(19 \%)$ used autoclaves and small sterilizers (61\%) as the main mode of sterilization in 1994. A number of hospitals did not have the facilities to perform any sterilization method. Contrary to 1994, in 2017, 31 out of 35 hospitals used autoclaves as the main method of sterilization. Sterilization charts were not available in the majority of hospitals (30/36) in 1994 whereas it was available in 32 hospitals in 2017. However, updated sterilization charts were maintained only in 29 hospitals even in 2017. There were three hospitals without the availability of gloves in 1994. The rest used reusable gloves. Two hospitals used autoclave technique for sterilization of used gloves and the remaining 31 hospitals reused gloves after washing with Savlon. But in 2017 all hospitals had disposable gloves.

Partograms was not available in 1994 whereas it was available in 29 hospitals in 2017. But only 23 hospitals maintained partograms regularly.

A direct observation of the hospital facilities and discussions with the health care personnel revealed that most divisional hospitals were not geared to provide maternal and newborn care. Although basic antibiotics were available, broad-spectrum antibiotics were not available in divisional hospitals. The availability of IV hydralazine, pethidine, magnesium sulphate and colloids were not satisfactory in both years (Table 4). At the time of the survey IV hydralazine, which is commonly used in hypertensive emergencies, was not available in 34 and 29 hospitals respectively in 1994 and 2017. Pain relief in labour was not practiced in both years. Availability of IV diazepam, IV adrenaline, IV drip sets, saline, lignocaine, 5\% dextrose, IV antibiotics and disposable syringes were sufficient in 2017 when compared to 1994.

In 1994, Ergometrine was used predominately as an oxytocic agent to manage the third stage of labour and it was available in $90 \%$ of the hospitals whereas in 2017 oxytocin was used as the principal uterotonic agent and it was available in $89 \%$ of the hospitals. Intra muscular diazepam (availability - 94\%) was the drug of choice in the management of eclampsia in 1994 whereas it has been replaced by intra venous diazepam (availability - 90\%) in 2017.

The second survey after two decades revealed only three hospitals (Thambuththegama, Kahatagasdigiliya and Padaviya) fulfilled criteria for

Table 3 - Availability of Essential instruments

\begin{tabular}{|lcc|}
\multicolumn{4}{|c}{ Table 3-Availability of Essential instruments } \\
\hline Resources & 1994 (36 Hospitals) & 2017 (35 Hospitals) \\
\hline Instruments & Availability & Availability \\
& N (\%) & N (\%) \\
\hline 1-Light sources & $15(41 \%)$ & $30(83.3 \%)$ \\
(spot lights for examination & & \\
and labour rooms) & $2(6 \%)$ & $35(100 \%)$ \\
2-Emergency trays & $8(22 \%)$ & $34(97.2 \%)$ \\
3-Oxygen cylinders & $19(52 \%)$ & $34(97.2 \%)$ \\
4-Suction apparatuses & $2(6 \%)$ & $6(16.7 \%)$ \\
5-Cut down sets & $2(22 \%)$ & $35(100 \%)$ \\
6-I.V. Cannulas & $25(69 \%)$ & $35(100 \%)$ \\
7-B.P. Apparatuses & $12(30 \%)$ & $32(91.7 \%)$ \\
8-Neonatal Resuscitators & & $35(100 \%)$ \\
9-Delivery sets & $23(63 \%)$ & 28 \\
Availability & NA & 6 \\
Complete & NA & 1 \\
Incomplete & NA & \\
Inadequate & & \\
\hline
\end{tabular}

Table 4 - Availability of drugs

\begin{tabular}{|lcc|}
\hline Resources & $1994(36$ Hospitals) & 2017 (35 Hospitals) \\
\hline Drugs & $\begin{array}{c}\text { Availability } \\
\text { (Number of hospitals) }\end{array}$ & $\begin{array}{c}\text { Availability } \\
\text { (Number of hospitals) }\end{array}$ \\
\hline Ergometrine & $32(90 \%)$ & $24(69 \%)$ \\
Syntocinon & $9(36 \%)$ & $31(89 \%)$ \\
Diazepam IV & $33(90 \%)$ & $32(91 \%)$ \\
IV Adrenaline & NA & $34(97 \%)$ \\
IV Hydralazine & $2(36 \%)$ & $6(17 \%)$ \\
IV Drip sets & $33(90 \%)$ & $35(100 \%)$ \\
Saline & $30(85 \%)$ & $35(100 \%)$ \\
Pethidine & $6(15 \%)$ & $16(46 \%)$ \\
Lignocaine & $12(33 \%)$ & $35(100 \%)$ \\
Colloids & NA & $9(26 \%)$ \\
5\% Dextrose & $25(66 \%)$ & $35(100 \%)$ \\
IV Antibiotics & $7(15 \%)$ & $32(91 \%)$ \\
Disposable Syringes & $8(16 \%)$ & $35(100 \%)$ \\
Magnesium Vials & NA & $5(14 \%)$ \\
\hline
\end{tabular}

anticipating safe deliveries (More than $50 \%$ of the recommended facilities by the $\mathrm{WHO}^{13}$. After two decades only Base Hospital Thambuththegama has been upgraded with the above recommended facilities. Even in 2017, divisional hospitals Kattiyawa, Kallanchiya, Ranorawa, Kapugollewa and Negampaha had less than $25 \%$ of the recommended facilities for the safe deliveries. 


\section{Long Drawn Complacency about Our Success Story}

The relatively low MMR rate in Sri Lanka has led to a long drawn complacency and inaction. The MMR of Sri Lanka ${ }^{14}$ is the lowest in South Asia. However, by 2015 all other South Asian countries have shown marked declines in the MMR and Maldives may become the country with the lowest MMR in South Asia sooner than later (Figure 2)

\section{Challenges in Leadership/ Good Governance and Accountability}

Better leadership and management with accountability, to provide direction to and gain commitment from partners and staff is needed to make the necessary system changes to achieve a further reduction in MMR. Efficient, creative and responsible deployment of people and resources through improved administration would result in better health services ${ }^{15,16}$.

Latest national maternal mortality review shows that $78 \%$ of the deaths have taken place in the hospitals and $59 \%$ were preventable. The factors that contribute to sub-standard care leading to such deaths include resource constraints, inadequate staffing and administrative failures. Establishing a system of accountability would enable the health care sector to minimise substandard care. Accountability should be applicable at every level of the hierarchy with necessary actions taken equally against all found to be negligent.

Out of the three types of accountability, financial, performance and political/ democratic, performance accountability is most important to minimize substandard care. Lack of performance accountability leads to covering up of erroneous commissions and omissions than rectifying them. Fact finding confidential inquiries into all maternal deaths with indemnity cover for healthcare workers so that corrective measures can be planned on correct information for the future are essential if accountability is to be established.

Figure 2 - Trends in MMR of Asian countries (Source: 1990 to 2013 WHO, UNICEF, UNFPA, and the World Bank estimates, 2014)

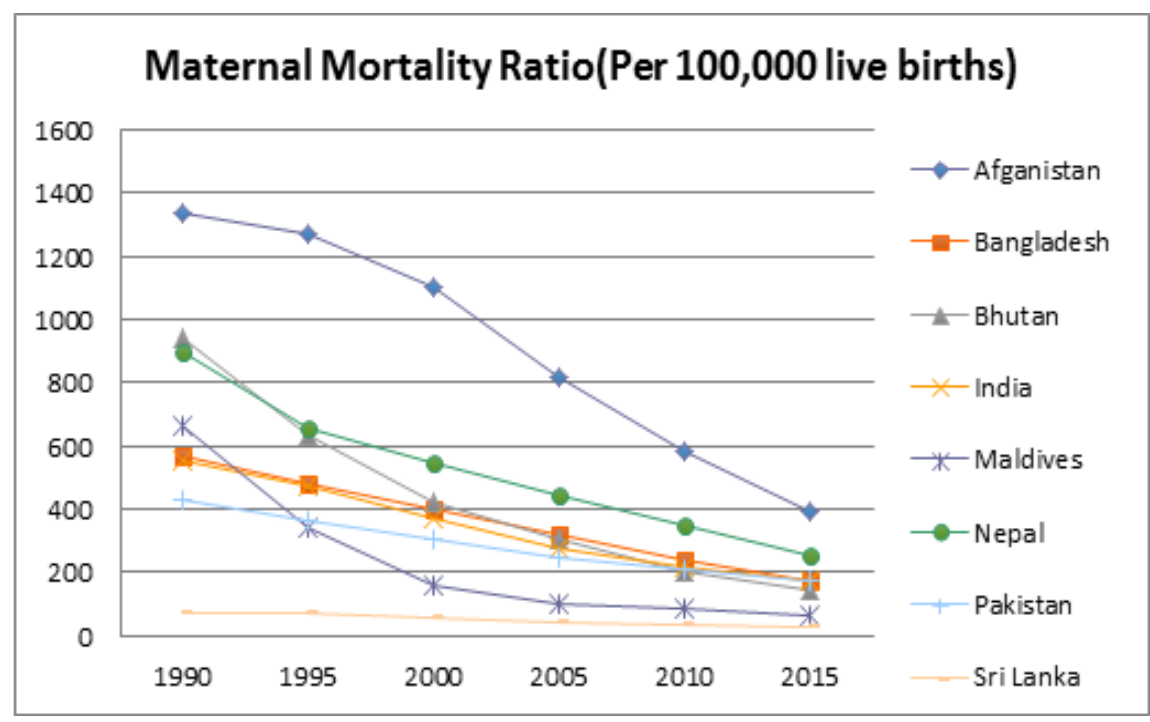

\section{Specific Interventions in the Health} Sector

Nepal's progress on maternal mortality has been hailed as a global success story and targeted interventions to the health sector are believed to have contributed to this immensely ${ }^{15}$.

Currently in Sri Lanka, the leading causes of maternal deaths are heart disease, respiratory diseases and obstetric haemorrhage. Strengthening the school medical inspections (SMIs) island wide to identify at risk individuals could contribute immensely to reduce such maternal deaths due to heart diseases. A system where those detected to have certain conditions at the SMI are followed up via a register that translates in the eligible couples register via the PHIs, PHMs and MOHs would serve this purpose. Defaulter identification and a second screening programme for those in child bearing age with the help of relevant specialists would further strengthen this.

Special attention should be given to women with pregnancies complicated by medical conditions, during antenatal period with the involvement of a multidisciplinary team (MDT). This needs to include both the public health sector and the curative sector staff working together both during the antenatal and the postnatal periods to cover needs including family planning. Availability of dedicated obstetrics intensive care units and high dependency units are also a must for successful management of such patients. Introduction of 'Red Flag" to identify all unwell pregnant mothers, similar to the programme by the Royal College of Obstetricians and Gynaecologists (RCOG) could be implemented in Sri Lanka as well ${ }^{18}$. Proper investigations of all cases of severe acute maternal morbidity should be done to learn lessons for future management.

Twenty-four hour obstetric, anaesthetic and blood bank cover should be available with specialists where possible. Dedicated obstetrics theatre facilities need to be made available. It is high time to establish super centers in each province. Minimum standards of infrastructure and other facilities should be ensured before making a hospital available for specialist care.

The mere availability of services would be of no use if the target population is unable to gain access, are unaware of the services or if healthcare workers cannot reach their population. Providing scooters to primary health care workers, readily available trishaws that can navigate difficult terrain and improved road networks and the introduction of "Red Book" by the FHB have been 
some of the major positive interventions in the recent past.

\section{Challenges in Service Delivery}

A universally accessible, free and an equitable health care system that functions on the said principles would provide means to address the stagnant MMR. Equity of access to service delivery is one of the system's strengths and has been achieved via several mechanisms ${ }^{16}$. However, our survey and the national survey on emergency neonatal and obstetric care (EmNOC) done in $2012^{19}$ identified several weaknesses in the system. The outof-pocket expenditure on health care was as high as $42.09 \%$ of total health expenditure in 2014 ${ }^{3}$. Provisions should be available to improve the universal coverage in areas with extreme poverty and difficult terrain. For example, in the estate sector, there should be transport facilities with ability to navigate the terrain, health care workers who could communicate with the native language, and qualified medical officers residing within the locality.

The major contributor to maternal deaths is the delay in treatment seeking $(61 \%$ - delay 1). Delay in reaching (5\% - delay 2) contributes the least. In this regard, the road network and readily available trishaws were major contributing factors in Sri Lanka. There are institutions still functioning without trained medical officers in blood banks, and many institutes still have only a single obstetrician. Although $93.1 \%$ of deliveries take place in institutions with EmNOC facilities, some institutes do not have the recommended facilities. In spite of national EmNOC survey recommendation to establish $24 \times 7$ services in all institutions manned by a specialist, still authorities have failed to implement it fully. This is partly responsible for the delay in treating (30\% - delay 3$)$.

Our survey and the national EmNOC survey clearly showed substandard infrastructure facilities in many institutions. Basic requirements such as electricity, safe water and transport facilities need to be available in all institutes. Obstetric ICUs and HDUs should be accessible. Measures should be taken to ensure that investigations could be done $24 \times 7$ without financially burdening the patient.

According to MMR survey 2015, unmet need for contraception accounted for nearly $23 \%$ of maternal deaths. Prevention of septic abortions is desirable and post abortal care should be strengthened. Avoidance of unwanted pregnancies and birth spacing by using modern family planning methods need to be promoted. The contraceptive prevalence rate (CPR) in 2007 was $68.4 \%$ in Sri Lanka, $84 \%$ in UK, $76 \%$ in US and $54.8 \%$ in India ${ }^{3}$. Despite the long-term efforts taken by the family planning services in Sri Lanka, there still appears to be a challenge to achieve the desirable CPR.

Many women avoid contraception for the fear of their partners' violent ${ }^{20,21}$. Societal and religious influences may also contribute to the lower rate of contraceptive acceptability. Contraceptive use among the vulnerable groups should be promoted. The availability and accessibility should be improved. It is important to establish distribution methods such as condom vending machines. The establishment of 0800-1600-hour family planning services via a dedicated clinic in all hospitals providing maternity services has been recommended, it is still not a reality. All contraceptive service providers should have updated knowledge, skills and attitudes to provide services. In addition, the public should be educated regarding the easily accessible sources of knowledge on this issue. Their fears and myths regarding contraception should be dispelled. A strong recommendation was made to the Ministry of Education and to the Ministry of Health by the SLCOG, to reconsider the establishment of an appropriate reproductive health module for school children as a measure to avoid unwanted pregnancies and consequently unsafe abortions.

Maternal mortality implies failure to guarantee women's rights. Gender equality has an important role to play in preventing maternal mortality. Around the world, one woman in every four is subjected to intimate partner violence $^{22,23}$. The violence may affect pregnancy outcome by increasing women's likelihood of engaging in harmful health behaviors such as smoking, alcohol/drug abuse and suicide. Therefore, it is necessary to identify gender based violence (GBV) as an important issue that has to be addressed very aggressively. Even though the College of Obstetricians has proposed to establish a Women Protection Authority to support the victims of GBV, the authorities have failed to do so and victims continue to suffer. As an alternative, there are 56 dedicated service centers established by the Ministry of Health. However, it is not sufficient to meet the demand.

\section{Challenges in Health Workforce}

Pregnancy out-come depends on the availability of a sufficient number of trained personnel who are competent, productive, responsible, courteous, kind, and responsive to the patients and to their families' needs.

There is gross maldistribution of all grades of health care staff in different institutes in relation to the workload as evident from the national EmNOC survey (Table 5). The maldistribution of staff is one of the major contributory factors in the 3rd delay. Maldistribution is largely due to political and trade union influences on the health authorities. Trade unions and politicians should be made aware of the consequences of their actions and they should be requested to keep away from influencing transfer procedures.

Evidence shows that prior training in obstetrics and regular in-service training of medical officers improve quality of care $^{24}$. At national level $65 \%$ of the Medical Officers, which include MOs and SHOs working in the maternity wards, have done an internship in Obstetrics.

Post-partum hemorrhage (PPH) continues to play a major role in maternal deaths in Sri Lanka, hence it is important to 
Table 5 - Workload for deliveries of selected categories of staff by District and Province (Source: EmNOC country report 2012)

\begin{tabular}{|c|c|c|c|c|c|c|c|}
\hline \multirow[t]{2}{*}{$\begin{array}{l}\text { Province/ } \\
\text { District }\end{array}$} & \multirow{2}{*}{$\begin{array}{l}\text { No. of } \\
\text { deliveries } \\
\text { in } \\
\text { specialist } \\
\text { units in } \\
2011\end{array}$} & \multicolumn{2}{|c|}{ Specialist obstetricians } & \multicolumn{2}{|c|}{$\mathrm{SHO} /$ Obstetric } & \multicolumn{2}{|c|}{$\begin{array}{l}\text { Midwifery staff* } \\
\text { (midwifery qualified } \\
\text { nurses and midwives) }\end{array}$} \\
\hline & & $\begin{array}{l}\text { No. of } \\
\text { specialist } \\
\text { obstetricians }\end{array}$ & $\begin{array}{l}\text { Average } \\
\text { no. of } \\
\text { deliveries } \\
\text { per month }\end{array}$ & $\begin{array}{l}\text { No. of } \\
\text { SHO/ } \\
\text { Obstetric } \\
\text { per month }\end{array}$ & $\begin{array}{l}\text { Average } \\
\text { no. of } \\
\text { deliveries } \\
\text { staff }\end{array}$ & $\begin{array}{l}\text { No. of } \\
\text { midwifery } \\
\text { qualified }\end{array}$ & $\begin{array}{l}\text { Average } \\
\text { no. of } \\
\text { deliveries } \\
\text { per month }\end{array}$ \\
\hline Western & 84840 & 39 & 181 & 141 & 50 & 666 & 11 \\
\hline Colombo & 44513 & 21 & 177 & 88 & 42 & 437 & 8 \\
\hline Gampaha & 23920 & 12 & 166 & 35 & 57 & 155 & 13 \\
\hline Kaluthara & 16407 & 6 & 228 & 18 & 76 & 74 & 18 \\
\hline Central & 43784 & 20 & 182 & 53 & 69 & 407 & 9 \\
\hline Kandy & 25427 & 13 & 163 & 32 & 66 & 253 & 8 \\
\hline Matale & 9979 & 3 & 277 & 10 & 83 & 103 & 8 \\
\hline Nuwaraeliya & 8378 & 4 & 175 & 11 & 63 & 51 & 14 \\
\hline Southern & 38519 & 14 & 229 & 45 & 71 & 185 & 17 \\
\hline Galle & 18392 & 7 & 219 & 22 & 70 & 104 & 15 \\
\hline Matara & 11720 & 3 & 326 & 12 & 81 & 34 & 29 \\
\hline Hambantota & 8407 & 4 & 175 & 11 & 64 & 47 & 15 \\
\hline Nothern & 15578 & 9 & 144 & 28 & 46 & 72 & 18 \\
\hline Jaffna & 7965 & 4 & 166 & 15 & 44 & 23 & 29 \\
\hline Kilinochchi & 2213 & 1 & 184 & 3 & 61 & 3 & 61 \\
\hline Mannar & 1155 & 1 & 96 & 3 & 32 & 35 & 3 \\
\hline Vavuniya & 3785 & 2 & 158 & 6 & 53 & 7 & 45 \\
\hline Mullaitiv & 460 & 1 & 38 & 1 & 38 & 4 & 10 \\
\hline Eastern & 29431 & 16 & 153 & 51 & 48 & 336 & 7 \\
\hline Batticaloa & 7543 & 4 & 157 & 15 & 42 & 124 & 5 \\
\hline Ampara & 5226 & 3 & 145 & 8 & 54 & 33 & 13 \\
\hline Kalmunai & 9147 & 4 & 191 & 14 & 54 & 102 & 7 \\
\hline Trincomalee & 7515 & 5 & 125 & 14 & 45 & 77 & 8 \\
\hline North western & 37222 & 13 & 239 & 49 & 63 & 375 & 8 \\
\hline Kurunegala & 23361 & 8 & 243 & 36 & 54 & 103 & 19 \\
\hline Puttalam & 13861 & 5 & 231 & 13 & 89 & 272 & 4 \\
\hline North central & 19911 & 6 & 277 & 20 & 83 & 199 & 8 \\
\hline Anuradhapura & 12712 & 3 & 353 & 11 & 96 & 148 & 7 \\
\hline Polonnaruwa & 7199 & 3 & 200 & 9 & 67 & 51 & 12 \\
\hline Uva & 20472 & 6 & 284 & 19 & 90 & 150 & 11 \\
\hline Badulla & 14912 & 4 & 311 & 14 & 89 & 110 & 11 \\
\hline Monaragala & 5560 & 2 & 232 & 5 & 93 & 40 & 12 \\
\hline Sabaragamuwa & 29754 & 10 & 248 & 44 & 56 & 425 & 6 \\
\hline Rathnapura & 19431 & 6 & 270 & 22 & 74 & 274 & 6 \\
\hline Kegalle & 10323 & 4 & 215 & 22 & 39 & 151 & 6 \\
\hline Sri Lanka & 319511 & 133 & 200 & 450 & 59 & 2815 & 9 \\
\hline
\end{tabular}


provide regular in-service training and emergency management drills to all health personnel. It is evident that standard courses for training in obstetric emergencies will become mandatory in many training programmes for junior residents and midwives. A standard accepted format of continuing medical education and training for specialists is also a timely need ${ }^{25}$. Safe motherhood programmes which were self-funded and organized by the SLCOG got the minimum support from the health authorities. Sadly, at times the participation of medical officers was also extremely unsatisfactory. However, the participation of nursing officers and midwives was good ${ }^{19}$. Unless a procedure to re-validate the medical council registration, which requires updating knowledge, skills and attitudes, is implemented, it would be difficult to ensure continuous professional development.

It has been observed in many occasions that either senior house officer or the junior most registrar has been assigned to carry out various types of highly complicated caesarean sections which have ended as disasters. It was found that in $26 \%$ direct obstetrics mortalities and in $38 \%$ indirect obstetrics mortalities the caesarean section has been done by the $\mathrm{SHO}^{19}$. In 2013, number of deaths following caesarean sections was 50 and of them, 15 were done by $\mathrm{SHOs}^{26}$. Increasing the cadre of the senior medical officers and specialists has to be done based on the intended quality improvement rather than the quantity that can be cleared by an individual.

The lack of adherence to the established guidelines as well as delays in transferring patients to tertiary care centers are some of the unaddressed reasons behind most of these maternal deaths. Even though updated guidelines are made available by the RCOG or the SLCOG, the acceptance and practice rates are seemingly poor.

In-service training of nursing officers is poor in many districts. In the Western and Sabaragamuwa provinces none of the training programmes could achieve sufficient coverage of training ${ }^{19}$. The training in labour room management has the highest coverage nationally. It is seen that most of the in-service training programmes conducted island wide have not covered adequate numbers of midwives ${ }^{19}$. An island wide shortage of midwives is evidenced by statistics from the FHB. Though they have advertised for 5000 new vacancies, they have received only 2700 applications ${ }^{14}$. In order to avoid the acute shortage of midwives they should be recruited from their residential areas. In addition, the minimum recruitment criteria should be relaxed but the training strengthened. To further improve the quality of midwives in the curative sector, they should be given an opportunity to obtain a bachelor's degree in midwifery like in some other countries ${ }^{27}$.

\section{Health Information System}

Discrepancies exist in health related data. For example, the MMR reported by the Registrar General's Department differs from the figure published by the Family Health Bureau. As our actions would be based on these figures, a proper health information system is essential to provide quality maternity care services ${ }^{28}$. A well-planned health information system ensures reliable and readily available health information for future planning. A proper health information system provides information on health determinants, performance, and health status. Lack of correct information on above three domains is a major obstacle in planning strategies for further reduction of maternal deaths in our country.

Record keeping by all levels of health care workers is extremely unsatisfactory. Many records are not only incomplete but also inaccurate and illegible. It is the responsibility of the Ministry of Health to establish a proper health information system soon. This will not only improve the quality of services but also the efficiency of the service providers.

\section{Medical Products, Vaccines and Technologies}

Drugs, vaccines, and medical supplies should be available in adequate quantities and of assured quality to provide optimum care. Shortage of drugs, vaccines, and medical supplies for maternal health is a challenge faced in many hospitals in Sri Lanka ${ }^{19}$. To ensure supplies are made available in a timely manner at any given hospital, a properly functioning island wide supply system should be established. All emergency obstetric drugs should be made available in any institute with trained staff, so that a rescue dose can be given till the patient is transferred.

Pregnant women are more susceptible for certain vaccine preventable infectious diseases. Sri Lanka now has a clearly demonstrable flu season. Influenza vaccination is part of maternal care in many countries. Introduction of influenza vaccination to pregnant women is a timely need. Further, antiviral drugs like oseltamivir should be available in hospitals.

Shortage of echocardiogram machines, multi functioning monitors, infusion pumps, ultrasound machines and operating theatre equipment etc. contributes to maternal morbidity and mortality. It is important that administrators understand that this equipment are part of routine obstetric care in current practice.

\section{Challenges in the Financial Sector}

Although labeled as a free health care system; Sri Lanka has a very high outof-pocket expenditure rate for health care. In $2014,56 \%$ of the total health expenditure of Sri Lanka was from the government while $44 \%$ was from the private sector. Out of the private expenditure on health, $96 \%$ was out-ofpocket expenditure ${ }^{29}$.

At present what is required is a rational and a sustainable financial plan that prioritizes areas like maternal and child health. Ideally, health policy should be independent of political agenda. Information on expenditure should be available to all stakeholders so that improvements could be made based on expert opinion.

In 2013 total health expenditure in Sri Lanka was $3.3 \%$ of the GDP, which amounted to Rs. 285 billion, and Rs. 13,841 per person (USD 107 per person). When compared to high income, upper middle income, low middle income and 
low-income countries, Sri Lanka shows the lowest in total health expenditure and has achieved relatively low MMR in South-East $\mathrm{Asia}^{30}$. This is due to the fact that Sri Lanka has adopted a pro-poor health policy ${ }^{31}$. However, the out-of-pocket expenditure in health care is high in Sri Lanka as mentioned previously ${ }^{29}$. This demonstrates partial failure of the "free" health care system of the country. Health Master Plan (2006 - 17) pointed out that total health expenditure should increase when life expectancy at birth increases. Accordingly, it should be at least 5.8\% of the GDP. In 2012 it was 3.1\% when the global average stood at $8.6 \%$. No programme can be sustained unless there is adequate financial support.

\section{Mass Media - A Hidden Treasure}

Globally, mass media campaigns are used for health promotion. Interventions through mass media produce positive changes by inculcating positive health behavior among individuals ${ }^{32}$.

Most maternal deaths are due to delay in seeking medical care. Hence health education programmes should be established to educate pregnant women, their spouses, and families on danger signs, which should prompt them to seek emergency medical care. As television is popular and mobile phone usage is high, it is recommended to deliver important health messages via these media. These messages should be palatable to less educated population as well.

Social media use is exceedingly common not only among the urban but also the rural community in Sri Lanka. Social media platforms could be effectively used for health promotion. Designated forums and websites could also be established for disseminating information to the public.

At present there is a system to communicate with field midwife through mobile phones. The relevant authorities have to further strengthen the system to educate women during their antenatal visits regarding communication with PHM. Further, midwives could be empowered to inform the relevant hospital to make necessary arrangement for emergency transportation.

Health promotional activities at antenatal clinics are a suitable method to disseminate knowledge to the public. As a proportion of pregnant women patronize the private sector it is important to involve the private sector in developing and disseminating health promotional material.

\section{Poverty Alleviation}

Poor women in remote areas are least likely to receive adequate health care. This is especially true for regions with low numbers of skilled health workers. Sri Lanka's current poverty line is moderate by regional standards, but below what one might expect from a country at Sri Lanka's level of development. However, extreme poverty is rare, estimated at 1.8 percent of the population in 2013. Living standards remain low, as nearly 45 percent of the population lived with less than $\$ 5$ per day in $2013^{33}$. As poverty is a major contributor to maternal mortality, consorted effort must be exercised collectively to alleviate poverty from our country.

\section{CONCLUSION}

Nearly 120 women die annually due to pregnancy related issues in Sri Lanka. For each of these deaths, there are many near misses and much longterm morbidity. These figures have not changed over the past two decades and $59 \%$ of deaths are due to preventable causes while $78 \%$ of deaths occur in hospitals. With the introduction of sustainable development goals, UN has recommended to reduce MMR by at least $7.5 \%$ each year between years 2016-2030. The annual reduction rate between years 2005-2015 has stagnated at $3.4 \%$ in Sri Lanka. Prompt action is needed if we are to achieve this goal. Our strategy so far has been to find faults of individuals rather than correcting system errors. It is advisable to introduce confidential inquiries into maternal deaths with indemnity cover for all health personnel sooner than later. It must be reiterated that without the indemnity cover, confidential inquiries have no place in our country. Lastly, it is high time to reformulate the existing strategies using the global trend with a local blend.

\section{ACKNOWLEDGEMENTS}

I am thankful to the Provincial Directors of Health Services and the Regional Directors of Health Services in Anuradhapura in 1994 and 2017 for their vital support; medical, nursing and midwifery staff for participating in the interviews; Prof Deepal Weerasekara, a colleague of mine and my team of medical officers in 1994 and pre-interns from Faculty of Medicine, University of Peradeniya in 2017 for their commitment in conducting the study and collecting data; Dr Nilmini Hemachandra (National Professional officer from WHO and Dr Kapila Jayaratne (Consultant Community Physician from FHB) for their valuable support; Prof Hemantha Perera, Dr Sarda Hemapriya, Dr Wimalasiri Abeykoon, Dr Eranthi Samarakoon, Dr Heshan Jayaweera, Dr Veranja Liyanapathirana, Dr Prabath Ranasinghe and Dr Manoji Pathirage for their advice; Dr Chathura Rathnayake, Dr Chaaminda Kandauda, Dr Aadithya Sirisena, Dr Madura Wanasinghe and Dr Tharaka Chandrathilaka for their help. I appreciate my beloved wife Nirmali, my son Samodha and daughter Sachithra for their valuable comments and tolerance during preparation of the script.

\section{REFERENCES}

1. Sima Sajedinejad, Reza Majdzadeh, Abou Ali Vedadhir, Mahmoud Ghazi Tabatabaei, Kazem Mohammad. Maternal mortality: a crosssectional study in global health. Globalization and Health 2015;11:4.

2, Wilmoth JR, Mizoguchi N, Oestergaard MZ, Say L, Mathers CD. A new method for deriving global estimates of maternal mortality. Stat Politics Policy 2012; $3(2)$. 
3. WHO, UNFPA, The World Bank and the United Nations Population Division. Trends in Maternal Mortality: 1990 to 2015 Estimates by WHO, UNICEF, UNFPA, The World Bank and the United Nations Population Division; 2014.

4. Alkema L, Chou D, Hogan D, Zhang S, Moller AB, Gemmill A, Fat DM, Boerma T, Temmerman M, Mathers C, Say L, United Nations Maternal Mortality Estimation Inter-Agency Group collaborators and technical advisory group. Global, regional, and national levels and trends in maternal mortality between 1990 and 2015, with scenario-based projections to 2030: a systematic analysis by the UN Maternal Mortality Estimation Inter-Agency Group Lancet. 2016; 387(10017):462-74

5. World Health Organization. Maternal Mortality: Fact sheet November 2016.

6. The World Health Organization. Trends in maternal mortality: 1990 to 2015. The World Health Organization, Geneva, 2015.

7. Family Health Bureau 2009. Annual Health Report 2006-2008. Ministry of Healthcare and Nutrition, Sri Lanka.

8. Family Health Bureau 2009. Annual Health Report 2006-2008. Ministry of Healthcare and Nutrition, Sri Lanka.

9. Health. Annual Health Bulletin. 2012.

10. Padmanadan P, Raman PS, Mavalankar DV. Innovations and Challenges in Reducing Maternal Mortality in Tamil Nadu, India. Journal of Health, Population, and Nutrition 2009;27(2):202-219.

11. World Health Organization. Maternal Mortality in 2005: Estimates developed by: WHO, UNICEF, UNFPA and The World Bank. Geneva: 2007.

12. United Nations Fund for Population Activities. The State of the World's Midwifery 2014: A Universal
Pathway. A Woman's Right to Health. New York: 2014.

13. World Health Organization. Essential elements of obstetric care at first referral level. Geneva, 1991.

14. El-Saharty S, Ohono N. South Asia's quest for reduced maternal mortality: What the data show. Investing in Health News and Views in Healthy Development, The World Bank. 2015. Available from http://blogs.worldbank.org/ health/south-asia-s-quest-reducedmaternal-mortality-what-datashow.

15. Egger O, Travis P, Dovio D, and Hawkin L (2005). Strengthening management in low income countries. 1st ed. Department of health system policies and operations. Evidence and informations for Policy, pp.3-8.

16. Rannan-Eliya R and Sikurajapathy L (2009). Good Practice in Expanding Health Care Coverage. Colombo: Institute for Health Policy.

17. Sharma J. (2016). Looking beyond Maternal Mortality Rates in maternal health interventions: Lessons from Nepal. [Blog] London School of Economics South Asia Centre. Available at: http://blogs. 1se.ac.uk/southasia/2016/07/20/ looking-beyond-maternalmortality-rates-in-maternalhealth-interventions-lessons-fromnepal

18. RCOG release: New measures to prevent maternal deaths. Royal College of Obstetricians \& amp; Gynaecologists. 2017. Available from: https://www.rcog.org.uk/en/ news/rcog-release-new-measuresto-prevent-maternal-deaths

19. National Emergency Obstetric and Neonatal Care Needs Assessment, Country report, 2012. (2014). Colombo: Family Health Bureau, Ministry of Health.

20. Dietz PM, Gazmararian JA, Goodwin MM, Bruce FC, Johnson $\mathrm{CH}$, Rochat RW. Delayed entry into prenatal care: effect of physical violence. Obstet. Gynecol 1997; 90:221-224.

21. Parker B, McFarlane J, Soeken K. Abuse during pregnancy: effects on maternal complications and birth weight in adult and teenage women. Obstetr. Gynecol 1994;84: 323-328

22. Ballard TJ, Saltzman LE, Gazmararian JA, Spitz AM, Lazorick S, Marks JS. Violence during pregnancy: measurement issues. Am. J. Public Health 1998; 88:274-276.

23. Campbell JC. Addressing battering during pregnancy: reducing low birth weight and ongoing abuse. Semin. Perinatol 1995;19:301-306.

24. Charles A Ameh, Nynke Van Den Broke. Making it Happen: Training health care providers in emergency obstetric and new born care. Best Practice and research Clinic Obs \& Gyn 2015;29:1077-1091.

25. William WK To. Training in emergency obstetric skills: is it evidence based? Hong Kong Med J 2011;17:141-6.

26. Jayaratne K. Findings of Maternal Death Reviews 2011-2012. Family Health Bureau. 2013.

27. Masoom M. Ensuring the First Breath: A Growing Accountability of Midwifery in Bangladesh. International Journal of Population Research 2017;2017:1-7.

28. Everybody's business strengthening health systems to improve health outcomes whose framework for action. (2007). [ebook] Geneva: World Health Organization, pp.1331. Available at: http://www. who.int/healthsystems/strategy/ everybodys_business.pdf

29. Guide to producing national health accounts. Available from: http:// www.who.int/health-accounts/ documentation/English_PG..pdf

30. Sarasi Nisansala Amarasinghe, et.al. Sri Lanka health accounts: national health expenditure 19902014 Colombo: Institute for Health Policy, 2015 140p. ; 30cm. - (IHP health expenditure series; No. 4 
31. McNay K, Keith $\mathrm{R}$ and Penrose A (2004). Bucking the Trend. How Sri Lanka has achieved good health at low cost - challenges and policy lessons for the 21st century. London: (C) Save the Children 2004, pp.4-6.
32. Wakefield, M.A., Laken, B., Hornik, R.C. Use of mass media campaigns to change health behavior. The Lancet 2010;376: 1261-1271.

33. The World Bank. Understanding poverty in Sri Lanka. The World Bank report part I. March 2, 2017 Available at http://www.worldbank. org/en/news/feature/2017/03/02/ part1-understanding-poverty-srilanka 